culated using the Kramers Kronig relations. Having the permittivity, the field fluctuations and corrections to the current fluctuations can then be calculated. After developing these results, Sitenko proceeds to apply them to the calculation of the fluctuations expected in unmagnetized and magnetized plasmas in and out of thermal equilibrium; to fluctuations in quantum plasmas and superconducting plasmas. He uses his calculated power spectra to discuss the dynamic friction and diffusion coefficients in a plasma, to calculate the energy loss of a fast charged particle passing through a plasma, and to calculate the differential scattering cross section for electromagnetic radiation and the cross sections for wave species transformation.

This is excellent work, but when Sitenko applies his methods to unstable plasmas I have reservations. The algorithm he has developed, which is, at least in its results, equivalent to a perturbation treatment of the dielectric, does not seem suitable if at any point the predicted fluctuations are large. This is exactly what happens for an unstable plasma; in some regions, Sitenko's method will predict unbounded fluctuations. In his illustrations, Sitenko is careful to avoid considera. tion of such points, but they remain in the spectrum and must be rendered finite by non-linear processes that are omitted from his treatment. Non-linear processes, however, will distribute the energy in these large fluctuations down into the part of the spectrum in the stable zone. Indeed, these difficulties arrive even in the simplest case, for the unmagnetized plasma can support undamped oscillations at the plasma frequency, and in particular, a calculation of the Raman line at $\omega_{p}$ in the scattered spectrum is disconcerting.

Because of these qualifications-and a fow others (for example, although three wave interactions in the same species are forbidden in the unmagnetized plasma, there is no universal law)-I would hesitate in recommending Sitenko's work to the novice, who might. in any case, be put off by the rather abrupt style. It is, however, a work highly to be recommended to the critical reader; it contains a great many useful results, will short-cut a great deal of work, and serves as an essential background to non-linear calculations and the study of plasma turbulence.

W. B. Thompson

\section{MORE TURBULENT PLASMA}

\section{Theory of Turbulent Plasma}

By A. A. Vedenov. (Achievements of Science: Plasma Physics.) Pp. iv +96. (Jerusalem: Israel Program for Scientific Translations; London: Macdonald-Oldbourne Press, 1966.) 31s. $6 d$.

THE theory of turbulence which is difficult enough in a classical fluid becomes even more complex in a plasma which can sustain many more modes of oscillation and the accurate description of which requires a larger number of fundamental parameters. The book under review has the encouraging feature of being short, less than 100 pages being devoted to ten chapters, some of which are only two or three pages long. Each chapter is devoted to one particular aspect of the subject and the logical development of the book makes it a good introductory text on turbulence for those with some knowledge of plasma physics. The description of turbulence can be highly mathematical, but it seems that an attempt has been made here to reserve the most difficult mathematics for the appendices at the end of the book and to appeal to physical intuition throughout the text.

The opening chapter is devoted to a formal description of a plasma in terms of magneto-gas dynamies, and this is followed by a review of the conditions in which the various kinds of plasma oscillations may exist. When these oscillations propagate as waves with decaying amplitudes the plasma retains its "laminar" state, but if the amplitude of any parameter such as density, velocity, electric or magnetic field is allowed to grow the plasma becomes unstable, turbulence sets in and the particle distributions depart from thermodynamic equilibrium. A number of these instabilities are already well documented and the third chapter which reviews them is followed by a discussion on the criteria for the onset of turbulence.

In a weakly turbulent plasma the energy contained in turbulent fluctuations is much smaller than that of the random motion of the particles and such a plasma is amenable to the quasilinear theory of the fifth chapter, which discusses the energy growth and decay of these fluctuations. The next two chaptor's show that it is possible in such a weakly turbulent plasma to consider the interaction between low and high frequency waves and to find equations which describe the situation when the energy in these waves is large onough for the interaction to become a "collision". The quasilinear treatment breaks down when these interactions aro so strong that the plasma is highly turbulent and the last three chapters deal with such a plasma.

Even in extreme turbulence some physical description is possible if the assumption is made that the velocity amplitudes of the particles in the strong oscillations are of the same order of magnitude as the phase velocity of the waves the growth of which is responsible for the onset of turbulence. The physical arguments for this assumption are put forward in the eighth chapter and the principle is applied to the examples of electron plasma waves and a turbulent plasma carrying a curront. The ninth chapter deals with the transport coefficients of a strongly turbulent plasma and the scattering of electromagnetic waves from such a plasma completes the text.

To sum up, this is the kind of introduction to a difficult subject which encourages further pursuit. JoHN PAIN

\section{SPECTROSCOPY LETTERS}

\section{Spectroscopy Letters}

An International Journal for Rapid Communication. Vol. 1, No. 1. Executive editor: James W. Robinson. Pp. 54. (Published monthly by Marcel Dekker, Inc., New York.) $\$ 3.00$ per volume.

THis is a new journal the aim of which is "to provide a means of communicating all valuable observations in spectroscopy to the community of spectroscopists in general". The first number contains a mixed bag of ten letters, four on electronic spectra, two on electron spin resonance, one on nuclear magnetic resonance, one on the theory of reflectance spectroscopy, one on flame emission with application to analysis and one on M.O. calculations.

There exist already quite a large numbor of journals in chemistry, physics and spectroscopy in which letters of this kind may be published. To judge from the slender evidence of this first issue, the established journals are doing their job very well.

R. F. BARRow

\section{OBITUARIES}

\section{Lord Florey}

Howard Walter Florey, who died on February 21, was a distinguished experimental pathologist, a great university teacher and an outstanding President of the Royal Society. In addition he played the crucial part in the greatest contribution medical science ever made to humanity, the production of penicillin and the 
other antibiotics which followed it. For this he was awarded, with Fleming and Chain, the Nobel Prize for Medicine of 1945 "for the discovery of penicillin and its curative value in a number of infectious diseases". It was a discovery the significance of which could be understood by everyone, and the world was eagor to honour those responsible. Florey was knighted in 1944; he was created a life peer in 1965 and became a momber of the Order of Merit later in the same year. He was recognized in France by the Legion of Honour and in America by the United States Medal for Merit.

Florey was born in Adelaide, South Australia, in 1898 and educated at St Peter's Collogiate School and the University of Adelaide, where he graduated in medicine. He went to Oxford as a Rhodes scholar in 1921 and from then on he made only occasional short visits to his native land; his life, his interests and his influence centred around Oxford. After working under Shorrington, he spent two periods in Cambridge separated by a year as a Rockefeller Fellow in America and with several shorter visits to European centres of research. In 1931 he was appointed to the chair of pathology at Sheffield, but in 1935 Florey went back to Oxford as professor and head of the Sir William Dunn School of Pathology. Sir Edward Mellanby played an important part in this appointment, which was a milestone in the history of pathology in Britain. For the first time a man trained in experimental physiology and looking at pathology with a physiologist's eyo had come into a position of influence in the subject. Soon afterwards another Australian, Cameron, brought a related experiinentally minded approach to pathology in London at University College Hospital Medical School. Between them they laid down a new pattern for teaching and research in the pathology departments of Britain and the Commonwealth.

The School of Pathology at Oxford flourished and during the years of Florey's direction, 1935-62, it produced a notable output of scholarly work and of workers who attained distinction in their own right. Florey's own interests ranged widely, but throughout his career there was a continuing preoccupation with the structure and function of the smaller blood vessels and their relation to the movement of lymph and cells in the process of inflammation. He was an experimentalist who was also intensely interested in the fine structure of cells and tissues; he enjoyed skilled manipulation and he was an enthusiastic photographer. All these qualities were given full play in his studies on capillary function and cell migration. They were manifested in his masterly use first of the rabbit ear chamber and other techniques for in vivo microscopy, and later of the electron-microscope.

The physiology of mucus secretion was another topic in which he did valuable work, particularly in clarifying its protective function in bronchus and intestine. Almost accidentally this initiated his first interest in the production of antibacterial agents by bacteria and fungi. Lysozyme is an enzyme present in significant amounts in human mucus as in many other cells and secretions. It is a glycosidase capable of breaking down the glycopeptide structure of the bacterial wall and it was first recognized by Fleming as an agent capable of killing and dissolving a harmless bacterium which he named Micrococcus lysodeikticus. The enzyme is present in large amounts in egg. white and was isolated from this as a protein of low molecu. lar weight by Roberts in Florey's laboratory. This work (n) lysozyme and the studies of Dubos on gramicidin, at about the same time, led Florey in 1938 to sense the need for a thorough investigation of some of the antibacterial substances produced by organisms. With the outbreak of war in 1939 the potential importance of any agent capable of dealing with bacterial infection of wounds probably accentuated his interest in the field, but Florey was insistent that this was not just "war work" but real science. Gramicidin, the products of Pseudomonas pyocyanea and Fleming's penicillin were all considered, but it soon became clear that the last was much the mos $t$ promising. Florey and Chain initiated a combined attack on the problem, a substantial team was built up and early in 1941 the offectiveness of crude penicillin in dealing with infections of animals and man by streptococci and staphylococci had been established. Methods of purification and concontration and a relatively accurate method of biological assay had been developed.

It then became Florey's task to persuade American authorities of the need to make major facilities available for the rapid development of penicillin production in quantity and to enthuse scientists and industrialists to co-operate. He was completely successful and the Oxford methods were developed, or superseded, so effectively that large amounts of penicillin were available for clinical use during the last stages of the Second World War.

Florey remained an active laboratory investigator all his life. After penicillin the main topies with which he was personally concerned were the relatively insoluble antibiotic, micrococcin, the electron-microscopy of blood vesscls and the nature of atherosclerosis. He was an excellent teacher, concentrating on the experimental sides of pathology and illustrating them largely with his own photographic material. With his colleagues at Oxford he published, in 1954, Lectures in General Pathology, a book which rapidly went through three editions and had a significant influence on the teaching of pathology throughout the world. In 1962 he resigned from his chair to become provost of the Queen's College, Oxford.

At the end of the Second World War, Florey was by far the best-known of Australian scientists and, largely under the influence of one of his former Australian colleagues at Oxford (Professor R. D. Wright), action was mooted both to attract Florey back to Australia and to raise the standard of medical research in the country. Florey was interested and in one way and another the idea broadened. Eventually the Australian Prime Minister, John Curtin, was persuaded that a national centre for advanced research in all fields of science would attract expatriates like Florey and Oliphant back to their own country. Out of this grew the Australian National University and its John Curtin School of Medical Research. Florey was largely responsible for the detailed planning and policy of the John Curtin School and many Australians were deeply disappointed when he preferred to remain in England instead of accepting its directorship. He did, however, maintain a keen interest in its progress and in 1965 he: became chancellor of tho Australian National University.

Florey become a Fellow of the Royal Society in 1941, received a Royal medal in 1951 and the Copley Medal in 1957, and filled the office of president with great distinction from 1960-65. During his presidency the society moved from Burlington House to its new quarters in Carlton House 'Terrace, five new Royal Society professor. ships were established, and, one hears, a significant new vigour was introduced into the society's business. He was one of the "great" presidents of the Royal Society and the first Australian and the first pathologist to hold the office.

In temperament Florey was reserved but sure of himself. 'To anyone outside the small group who knew him intimately, his chief characteristic was his clear common sense and his intense sense of obligation toward and responsibility for his scientific colleagues. He was insistent that any scientist in his laboratory should be adequately paid and have the best research facilities that he could obtain for him. For Florey, financial security and prestige were more important in stimulating a scient ist to good work than any sense of dedication. It was a manifestation of the same absence of what he regarded as humbug that he had no liking for speculation. An idea was not worth having unless it could be used to help design an experiment which would or could in principle give a definitive result. Perhaps this is what made him one of the most effective medical scientists of his generation. 